\title{
Economic Justice, Climate Change by Gender: The Case of Market gardeners in the Coastal Republic of Benin
}

\author{
Acacha-Acakpo Hortensia V. ${ }^{1}$ \\ ${ }^{1}$ National School of Applied Economics and Management (ENEAM / UAC), Republic of Benin \\ Correspondence: Acacha-Acakpo Hortensia V., National School of Applied Economics and Management \\ (ENEAM / UAC), Republic of Benin. E-mail: horcacha@yahoo.fr
}

Received: November 10, 2018

doi:10.5539/jsd.v12n3p168

\author{
Accepted: December 14, 2018 Online Published: May 30, 2019 \\ URL: https://doi.org/10.5539/jsd.v12n3p168
}

\begin{abstract}
Climate change affects men and women differently, specifically in income-related to activities. In the case of market gardening, cropping techniques, input costs and quantities used vary according to sex. This work analyzes economic justice in this context of unequal access to resources by gender. The regression analysis on data collected from actors in the market gardening sector showed that women have lower incomes than men because their production related to climate change are too low. Women can not do all activities and transform them into production costs. The benefits are low and slow down their buying and making provision.
\end{abstract}

Keywords: B54, D33, D63, J43, K36

\section{Introduction}

Climate change today is a potentially major threat to the environment and sustainable development. According to Report No. 4 of the Intergovernmental Panel on Climate Change (ICG), they are manifested through various trends such as rising temperatures, rising sea levels, increased variability in rainfall which influences the agricultural seasons, the resurgence of extreme phenomena such as droughts and floods, etc. Global observations now show a general upward trend $\left(0.6^{\circ} \mathrm{C}\right.$ to $\left.-0.2^{\circ} \mathrm{C}\right)$ of the average surface temperature, which is linear and almost twice that of the period from 1906 to 2005 , i.e. $0.13^{\circ} \mathrm{C}$ per decade (CRA, 2010). Africa and western Asia would see their production decline thus $25 \%$ for $3{ }^{\circ}$ to $4{ }^{\circ} \mathrm{C}$ of average temperature increase and famine would affect 500 million more people. In this context, 1 / 6eme of the population of these two continents depends on the products of the sea and agriculture which, with a social weight that goes well beyond the $3 \%$ to $5 \%$ of the gross domestic product in the developed economies, will continue to support the large fraction of the world population that lives With less than US \$ 2 per day. At the health level, there have been degradations in the hot regions which, on average, have resulted in an additional 150000 deaths per year since 1970 .

The diagnosis made on the effects of climate change in Benin's 2008 investment report shows that the country's agro-ecological zones are vulnerable to the three major climatic risks of drought, late and violent rains and floods. Heavy winds and excessive heat are likely to become increasingly important in some localities with high resource exposure (catchments, subsistence agriculture and water resources) to social groups such as smallholder farmers Farmers, market gardeners, pastoralists, fishermen and emerging farmers.

In Benin, there are four climatic subsets: a major rainy season from April to July, a small dry season from August to September, a small October rainy season and a large dry season from December to March. In addition, long-term hydrological observations show a general decrease in average rainfall of about 15 to $30 \%$ depending on the area and a decrease in the number of rainy days and the duration of the rainy seasons, In surface waters at the level of the main basins ( 40 to $60 \%$ ). Under these conditions of difficult farming and the use of multiple species and varieties, research results indicate that the yield level of Beninese agriculture is below the potential of cultivated varieties with a considerable drop in harvest of the order of: 3 to $18 \%$ all crops combined.

While, the Beninese economy despite the efforts made to a GDP that remains dissolved of the minimum rate of 7\% required to achieve the MDGs. It is characterized by a strong predominance of the primary sector, which occupies about $60 \%$ of the population and contributes to $36.6 \%$ of GDP. Moreover, according to human poverty indicators, $4.3 \%$ of the Beninese population is affected (MEHU, 2011). 
Faced with climate change and growing poverty; It is necessary to apprehend the effects of changes in temperature and precipitation on the primary sector and, consequently, to improve the living conditions and sustainable income of the population in Benin.

Several strategies are adopted by farmers and especially market gardeners to counter the difficulties. To this end, the modification of the dates of semi and harvest, the use of seed and fertilizer variety, irrigation, use of tractors etc. are practiced by farmers. However, these different measures have not yet had the same effect in reducing the negative effects of climate change on agriculture. Thus, our work aims to evaluate empirically the effectiveness of these adaptation measures or strategies on climate change mitigation. What are the effects of market gardening strategies on agricultural agricultural productivity? Do the strategies vary by gender?

\section{Literature Review}

\subsection{Climate Change and Economic Growth}

The development of adaptation strategies is an inescapable way to reduce the damage expected in the short term (Pielke, 1998). However, adaptation could be achieved through technological innovation. According to Issa (1995); Adaptation can be summarized as a set of readjustments within natural and human systems and in curative and preventive response to current or future climate stimuli or their effects with a view to mitigating or benefiting from their nuisance. Technological innovation is therefore the result of the readjustment made to stimulate growth.

\subsection{Economic Foundations}

The issue of climate change is essentially due to its global public good character. As with any public good, decentralized market systems do not provide a socially optimal supply. By its global nature, an adequate public policy presupposes the voluntary restriction of sovereignty for States under negotiated agreements.

The provision of global public goods can be used under two management regimes. The most extreme is the uncooperative regime without international agreements. This is the case for climate change until today. In this situation, countries and individuals tend to act according to their own interests, and the overall balance resulting from their decisions is non-cooperative in nature. Although perfect cooperation is very difficult to obtain, the World Trade Organization (WTO) or the Montreal Protocol tries to promote a free and open trade.

\subsection{Climate Change and Gender Business and Economic Justice for Women}

Economic justice for women is not only about integrating them into a given economic model but also improving their access to economic resources, decent work and control over their own time. It also implies the promotion of women's self-determination and autonomy in economic choices at all levels, from decisions related to household management to those taken in national parliaments and international institutions.

Economic justice also requires the analysis of labor rights, global governance and the informal economy. It promotes adequate universal social protection to alleviate poverty and provide a basic level of well-being for all, especially women most affected by lack of protection and most likely to be excluded from benefits Basis of employment. It thus contributes to collective action while safeguarding specific interests.

Integrating gender and justice into economic debates has a direct impact on food security, livelihoods and the need for unpaid care and domestic work, which falls disproportionately on women. A fair transition to post-carbon or low-carbon economies is needed to mitigate these impacts.

\section{Theoretical Framework}

This work is based on the theoretical analysis of Elinor Omstrom which perfectly demonstrates in his work that the management of natural resources must be made as close as possible to human control and not remote in governmental spheres, whether national or international. The author's reflections therefore take into account individual and collective interests in a given context. The author has demonstrated that overexploitation of common property is avoided when users organize themselves to manage these assets, whether they are pastures, fishing grounds or groundwater, Mechanisms of their own favoring relations of trust and reciprocity. It proposes a third way, between the state and the private, collective mobilization at the local level around the resources to be managed.

Starting from this reflection in the context of this study, it is necessary to first identify the strategies that the market gardeners espouse themselves in the face of climate change and then make a comparison in terms of access, use and control of Resources and means of production according to gender. Finally, the analysis in this study could extend to the distribution of profits and the management of losses. 
Gender-based economic justice, in the context of climate change, analyzed the resources linked to human and financial capital with respect to gender and, on the other hand, the accessibility of women to natural factors of production and Distribution The question is whether women and men benefit from the equitable resources of production that are here human capital and financial capital based on the Cobb-Douglas production model. Human capital is represented by the following factors: Level of education, Practical training in market gardening and capital investment represented by the means of production and management.

\subsection{Methodology of the Study}

The analysis examines access to and control over the means and resources of the market gardening sector in relation to climate change by gender. The study is in cross section. In the Littoral department in Benin, vegetable growing is the most practiced and more vulnerable to climate change because it requires a lot of water, fertile land and special attention for watering, weeding, phytosanitary and other treatments.

\subsection{Sampling}

Thus the population of this study would consist of all the vegetable of the department. Sampling is a reasoned choice based on gender differentiation. Indeed, there are more men in the sector than women and even less, women heads of household market gardeners. Very often these latter accompany their husbands to the fields. Faced with this inequality in this sector, all women market gardeners were taken into account in the survey and then supplemented with an equal number of market gardening men in the identified area. This has allowed us to have an almost equal number of men and women.

The variables of the study are forty-seven. These variables took into account the different resources involved in the cultivation of market gardening, from access to land and other means of production, to cultural techniques, Phytosanitary treatments, followed by performance, price and marketing variables. Some variables are quantitative such as price, yield, age area and others are qualitative such as pest control, weeding, weeding or yes or no

The main tool of the collection is the questionnaire containing many closed questions and some open questions.

\subsection{Analysis Framework}

After the field investigation, the collected information was entered, cleared. Tests were made to compare the mean proportions of each variable using STATA 12 software for men and women. These tests have specified two categories of variables. According to $\mathrm{H} 0=\mathrm{H} 1$ or $\mathrm{H} 0$ different from $\mathrm{H} 1$. The variables that indicate equal access to and control of resources among men and women, and variables that show that men have more access and control over certain resources than women.

Estimation of the model

Form of the model and choice of variables

For the verification of our hypothesis we start from the Cobb Douglas model which is as follows:

- $\mathrm{Y}$, where $\mathrm{Y}$ is the level of income from market gardening, $\mathrm{K}$ is the capital invested and $\mathrm{L}$ is the amount of labor used. Applying the logarithm function to this model, its econometric form gives us its linear form which follows: or again with $\mu \mathrm{i}$ the error term. From this model, we retain the following for our study:

- Y (income), K (a combination of inputs, improved seeds) and L (number of weeding and / or watering, treatment).

\section{Estimation model and verification tests}

After selection of the variables of the study model, the expression of the model of the study is written as follows:

C (3) * FERTILIZER, NPK, phytosanitary treatments + C (4)* FERTILIZER + C (5) * NUMBER OF DISARMAGE + with $\mu$ i the term $d$ 'error.

(D) $+\mathrm{C}(1)+\mathrm{C}(2) *$ social and economic capital $+\mathrm{C}(3) *$ means of production $++\mathrm{C}(5) * \mathrm{D} 1+\mathrm{C}(6) * \mathrm{D} 2+$ with $\mu$ i the error term.

Knowing the values of the variables explained and the explanatory variables of the model, we will estimate the values of the coefficients by simple linear regression and judge their statistical significance by the Ordinary Least Squares (OLS) method. The significance threshold used is $5 \%$ and a coefficient will be said to be significant when the probability associated with it is less than 0.05 . Estimates are made in an instant cross-section on observations from the survey. 


\section{Presentation of the Results}

4.1 Profile of Respondents

Table1. Profile of respondents in the sample

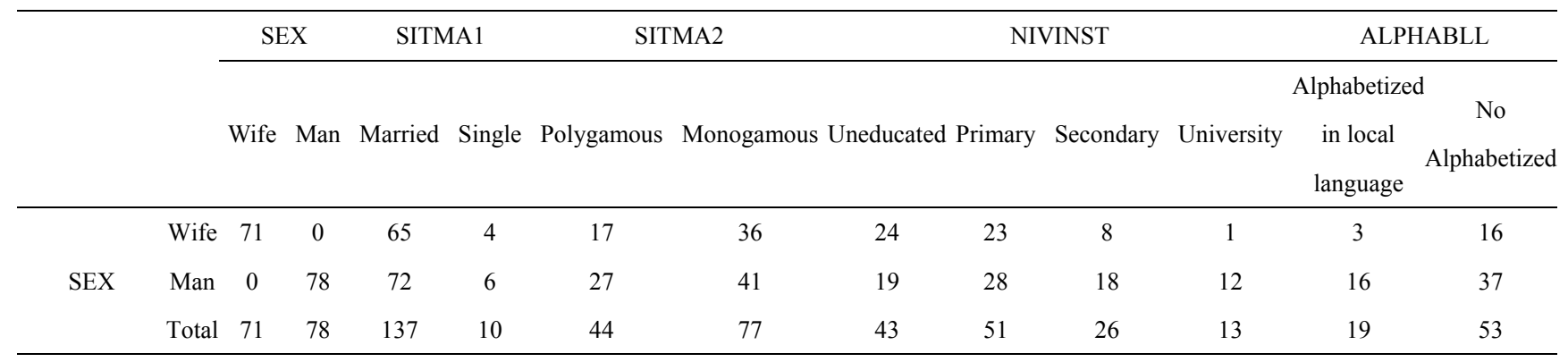

Source: Survey 2017

The table above presents the characteristic features of the sample studied. This consists of 71 women and 78 men. Of the 71 women surveyed, 65 are married, including 17 polygamous and 36 monogamous; And 4 are unmarried, while of the 78 men surveyed, 72 are married, including 27 polygamous and 41 monogamous; And 6 are single. In terms of educational attainment, 24 women are uneducated, 23 have a primary level, 8 have a secondary level and only one has a university level. On the male side, 19 are uneducated, 28 have a primary level, 18 have a secondary level and 12 have a university level. In addition, only 3 women are literate in the local language and 16 are one literate compared to 16 literate and 37 ducated men.

4.2 Resources and Means of Production of Access and Equal Control by Men and Women in the Market Gardening Sector

In this section, we have analyzed the conditions of equal access to factors and means and resources of production by men and women, and then the most significant coefficients are highlighted. These include:

Table 2. Variables for which the proportion of women is equal to that of men

\begin{tabular}{|c|c|c|c|c|}
\hline Code of variables & Variable name & Coefficients & P-value & Significance of product flow \\
\hline gift & gift & .189242 & 0.855 & Not significant \\
\hline LOCAT & leasing & -.7826186 & 0.061 & significant \\
\hline FERTTS1 & Type soil fertility1 & .5400712 & 0.335 & significant \\
\hline BLT & integrated & .459532 & 0.748 & Not significant \\
\hline RLUT1 & Elimination of pests & -.360002 & 0.437 & Not significant \\
\hline WELL & Well & .1335137 & 0.850 & Not significant \\
\hline Water & River & .1116952 & 0.800 & Not significant \\
\hline ARROS & watering & .4904402 & 0.299 & Not significant \\
\hline RACCOR & fittings & .5320509 & 0.249 & Not significant \\
\hline DEFRICH & Clearing & -1.81086 & 0.005 & significant \\
\hline THE DIRT & plowing & .4552313 & 0.557 & Not significant \\
\hline DIGUET & bunds & -13.8713 & 0.989 & Not significant \\
\hline $\mathrm{K} 2 \mathrm{SO} 4$ & K2SO4 & .2610419 & 0.596 & Not significant \\
\hline \multirow[t]{2}{*}{$\mathrm{MCBC} 2$} & White Fly & -.474622 & 0.380 & Not significant \\
\hline & Stems c1 & 7635862 & 0.191 & Not significant \\
\hline
\end{tabular}




\begin{tabular}{lllll} 
FRUC1 & insecticides to protect the fruits & -.869134 & 0.055 & Not significant \\
TERMC3 & Termite Pest & -.709838 & 0.537 & Not significant \\
& Snail1 & 1.703717 & 0.046 & Not significant \\
& Snail2 & 17.99109 & 0.996 & Not significant \\
VERC1 & worming & .2677208 & 0.772 & Not significant \\
VERC2 & wormingC2 & .7703726 & 0.584 & Not significant \\
NEMC1 & nematicides & .3909506 & 0.349 & Not significant \\
SOUC1 & rodenticide C1 & -1.13173 & 0.245 & Not significant \\
SOUC2 & Rodenticide C2 & -16.1030 & 0.990 & Not significant \\
\hline
\end{tabular}

Comment: The table 3 above shows on the one hand the variables for which the proportion of women with access is substantially equal to that of men who also have access. Among these variables, we distinguish mainly production factors and production techniques, such as the control of insect pests. These two sets of variables are mainly characterized by their ease of access compared to those that will be presented later in Table 3 . This allows women access like men. On the other hand, compared with the influence of these variables on the income of vegetable, the results reveal that only the variable "clearing" is significant. Clearing is an activity that does not require special effort. It can be practiced by men as women. It is also a key factor for crop development and influences yield.

4.3 Resources and Means of Production for Unequal Access and Control by Men and Women in the Market Gardening Sector

Table 3 below shows the variables for which the proportion of women with access is different from that of men.

Table 3 Variables for which the proportion of women is different from that of men

\begin{tabular}{|c|c|c|c|c|}
\hline Code of variables & Variable name & Coefficients & P-value & Significance of product flow \\
\hline PURCHASE & Purchase of land & -.0642897 & 0.903 & Not significant \\
\hline HERIT & Inheritance of land & -.013435 & 0.975 & Not significant \\
\hline METAY & Earth metering & -16.34457 & 0.995 & Not significant \\
\hline Hillside & Hillside & .9288797 & 0.042 & significant \\
\hline Low background & Low background & .9117911 & $\mathbf{0 . 0 3 3}$ & significant \\
\hline PLATO & Tray & .2019739 & 0.654 & Not significant \\
\hline INONTS1 & Flood type sol1 & .4567584 & 0.269 & Not significant \\
\hline TERMC1 & Ants $\mathrm{C} 1$ & .1144104 & 0.870 & Not significant \\
\hline TERMC2 & Ants C2 & -.2876821 & 0.835 & Not significant \\
\hline NEMC2 & Nematodes $\mathrm{C} 1$ & -.0397403 & 0.954 & Not significant \\
\hline PHYS & Physical Wrestling & -.8109302 & 0.194 & Not significant \\
\hline RLUT2 & Reason for protection of young plants & -.6613107 & 0.197 & Not significant \\
\hline RLUT3 & Limitation of parasitic pressure & .6358611 & 0.228 & Not significant \\
\hline RLUT4 & Biological Control Tedious and need for regular follow-up & .3878802 & 0.397 & Not significant \\
\hline WATER & Water & -.8538072 & 0.206 & Not significant \\
\hline EPLUI & Rainwater & -.4723673 & 0.468 & Not significant \\
\hline 12.FORAG & Drilling & -.7298011 & 0.257 & Not significant \\
\hline
\end{tabular}




\begin{tabular}{|c|c|c|c|c|}
\hline 13.TOURNIK & Turnstile & -.638541 & 0.467 & Not significant \\
\hline 14.МОТРОМ & pump & -.7648513 & 0.176 & Not significant \\
\hline 15.ASSO & Association & -.2390647 & 0.432 & Not significant \\
\hline STAKE & Picket & -1.353793 & 0.027 & significant \\
\hline FUMFON & Furmur of funds & .0282521 & 0.966 & Not significant \\
\hline Planch & Boards & -.3997292 & 0.600 & Not significant \\
\hline BILLON & the ridges & -.2891408 & 0.735 & Not significant \\
\hline NOTILAGE & Without Labor & -.4074224 & 0.671 & Not significant \\
\hline LABPLA & Plowing & -2.032625 & 0.000 & significant \\
\hline GESTBIO & Biomass Management & -.1445763 & 0.719 & Not significant \\
\hline FERTI & Fertilization of land & .2489702 & 0.385 & Not significant \\
\hline UREA & Urea & -1.797026 & 0.115 & Not significant \\
\hline NPK & NPK & 1.244402 & 0.274 & Not significant \\
\hline CHEC1 & C1 Track & -.6074393 & 0.374 & Not significant \\
\hline CHEC2 & C2 Tracks & .4601404 & 0.493 & Not significant \\
\hline VIRC1 & Virose $\mathrm{C} 1$ & -.1708351 & 0.865 & Not significant \\
\hline VirC2 & Virose C2 & -.0681413 & 0.933 & Not significant \\
\hline FLEC1 & C1 wilting & -.3154588 & 0.628 & Not significant \\
\hline FLEC2 & C2 wilting & -.5865547 & 0.450 & Not significant \\
\hline $\mathrm{MCBC} 1$ & White Fly C1 & -.6070248 & 0.422 & Not significant \\
\hline $\mathrm{MCBC} 2$ & White Fly C2 & .2593736 & 0.764 & Not significant \\
\hline MLCC1 & Chemical Control Method C1 & .1159017 & 0.880 & Not significant \\
\hline MLCC2 & Chemical Control Method C2 & .0108115 & 0.987 & Not significant \\
\hline MLBC2 & Control method Biological C1 & -.2293733 & 0.479 & Not significant \\
\hline MLBC1 & Control method Biological C2 & -.4481801 & 0.728 & Not significant \\
\hline ML2C1 & The two methods of control C1 & .2382199 & 0.824 & Not significant \\
\hline ML2C2 & The two methods of control C2 & -.3402386 & 0.779 & Not significant \\
\hline PARAS & Parasite Pressure & .1264378 & 0.802 & Not significant \\
\hline FLIGHT & Flight & -.1471675 & 0.850 & Not significant \\
\hline Mirri & Lack of irrigation equipment & -.2908457 & 0.619 & Not significant \\
\hline PULVE & Spray & .6882794 & 0.396 & Not significant \\
\hline SUFALI & Food self-sufficiency & -.519063 & 0.534 & Not significant \\
\hline FINTONT & Financing of Tontines & -.7069105 & 0.510 & Not significant \\
\hline VALORI & Valorisation of acquired knowledge & -.8666596 & 0.386 & Not significant \\
\hline
\end{tabular}

\section{Commentary}

We note that the variables in Table 3 are competing variables because of their utility. These are mostly variables that require enough means (Land Purchase, Hillside, Low background, Drilling, Urea or NPK); Which limits 
women's accessibility because women's resources are limited. Also other factors like plowing flat, picket are also variables that requires enough energy. This prevents women from practicing as women. An estimate of vegetable income represented by the flow of commodities on these variables shows that only the variables "picket planting" and "flat plowing" that require enough energy and land-use variables " And " bottom land " which requires enough financial means for upstream purchase are significant. This explains the low income of women compared to men.

\section{Conclusion}

The objective of the work is to measure the access and equal control of men and women to resources and means of production in the market gardening sector. The comparison of mean and two multiple regressions to assess the significant coefficients of the equality and non-equality variables was performed. The results show that women have difficulty accessing the relevant and essential means of production such as land and cultivation techniques that require a lot of effort.

On the other hand, they are able to do activities and control yield-related inputs such as men. These results indicate an inequality in the access and control of resources and means of production on income in the market gardening sector. However, variables that seem to offer the same opportunities in terms of access and control still benefit men by positively influencing their income during the sale of market gardening products than women. These analyzes explain the economic interests of man in the face of degradation linked to the management of the environment.

Like Boyce (1994), these results indicate that men are taking advantage of the weakness of women to further degrade the environment. Democracy at the grass roots and equity are two concepts necessary to integrate into environmental protection policies. Unfortunately, the marginalized women in this sector of market gardening are more limited in access to public resources and in an underdeveloped country such as Benin the civil society that could carry social movements of this kind of theme is subordinated to The political society Heller (2012). For Kashwan (2017), in a study on the relationship between inequalities and environmental management in 137 countries, these results show that in countries where democracy is weak, land inequality is very striking, unlike countries with strong democracies. Grassroots democracy could therefore contribute to the reduction of gender inequalities in the market gardening sector and thus to economic justice.

\section{References}

Boyce, J. (1994). Inequality as a cause of environmental degradation. Ecological economics, 11, 162-178. https://doi.org/10.1016/0921-8009(94)90198-8

FAO. (2009, October). "The Special Challenge for Sub-Saharan Africa", presentation at the high-level expert forum "How to Feed the World 2050," Rome.

Issa. (1995). Analysis of Benin's Ecosystems in Review of EBA, Number 7, 4 134-145p.

Kashwan, P. (2017). Inequality, democracy and environment: a cross national analysis. Ecological Economics, 131, 139-151. https://doi.org/10.1016/j.ecolecon.2016.08.018

Pielke, R. (1998). Interactions between atmosphere and terrestrial ecosystems. Rethinking the role of adaptation in climate policy, in science policy colorado, 161.

\section{Copyrights}

Copyright for this article is retained by the author(s), with first publication rights granted to the journal.

This is an open-access article distributed under the terms and conditions of the Creative Commons Attribution license (http://creativecommons.org/licenses/by/4.0/). 